\title{
DESIGN AND ANALYSIS FOR MILLING OF TI-6AL-4V USING
}

\section{OPTIMAL END MILL}

\author{
ARAVIND RAJ. B. R \& P. JEYARAMAN \\ Department of Mechanical Engineering, Veltech Rangarajan Dr. Sagunthala \\ $R \& D$ Institute of Science and Technology, Avadi, Tamil Nadu, India
}

\begin{abstract}
Ti-6Al-4V has much advantage in mechanical properties, but it is difficult in machining process. It is well known that exhaustive research have been already conducted over the issues on surface alterations. Still, there exists a gap to reduce these damages by improving tool design for a smoother cutting process and to avoid heavy heat generation. In this project, after an exhaustive survey we have decided to adopt Tungsten Carbide for the milling process. All basic material properties (such as strength, rigidity, wear resistance, minimum dimensions weight, safety, reliability \& tool life) were considered while designing the tool for the machining process. In this project, cutting tool of Tungsten Carbide is used as a cutting tool for machining titanium alloy. Theoretical result of Tungsten Carbide acting on titanium alloy is done with help of ANSYS software. In the present approach, the effects of various parameters of cutting process i.e. calculating, testing and designing are used.
\end{abstract}

KEYWORDS: Milling, ANSYS Software \& Tool Life

Received: Apr 22, 2019; Accepted: May 13, 2019; Published: Jun 17, 2019; Paper Id.: IJMPERDAUG20197

\section{INTRODUCTION}

Machining is a manufacturing operation, in which, material is machined smoothly according to the given condition. Materials are removed in the form of chips by suitable cutting tool against the work piece. Some of the machining process like turning, drilling, and milling mostly carried in all types of machining process. In this concern, turning operation is done with the help of lathe for material in the form of cylinder. The drilling operation used for drilling of holes in the required diameter. Compare to drilling and turning, milling operation is used for machining of complicated shapes in both cylindrical and flat material. Operations like slotting, gear cutting, keyways etc. can be done with the help of milling operation. In milling process, different types of cutting tool are used to cut the given work piece. They are (i) End mill, (ii) face mill and (iii) Peripheral mill. Among these types, end milling cutters are commonly used cutters for horizontal milling operation. They are classified into three types, namely flat end mill, ball nose end mill and bull nose end mill.

\section{Ti 6Al 4V}

Titanium alloy are lightweight and corrosion resistance materials. They have the highest strength to weight ratio as all commonly used metals, up to 550 degree Celsius. Titanium alloys are using aerospace of high specific strength, and the elevated temperature of titanium milling aerospace is increasing in industrial and commercial applications. High speed machining process is of growing industry, not only allow for large material removal rates, and positively influence the properties of finished work piece. 


\section{Influnces of Titanium Properties on Machinability}

Titanium and its alloy presents low machinability due to their low thermal conductivity, high reactivity, low elastic modules, high hardness and strength at elevated temperature and peculiar work hardening feature.

\section{Tungsten Carbide}

Carbide metals have a number of valuable material properties; make them the promising materials for use in various new fields and increase the technology. They are used in various cutting processes. They are also used in catalytic applications. Tungsten carbide is one of the best carbides used.

\section{Properties of Tungsten Carbide}

Mechanical properties

- $\quad$ High temperature withstands capacity.

- Carbide tool maintain sharp cutting edge better than other tools.

- It can machine the material faster.

- Hardness of this material is high.

Table 1: Properties of Tungsten Carbide

\begin{tabular}{|l|l|}
\hline Melting point & 2,870 \\
\hline Boiling point & 6,000 \\
\hline Thermal conductivity & $84.02 \mathrm{~W} / \mathrm{m} . \mathrm{k}$ \\
\hline Extreme hardness & $1700-2400$ (vicker's scale) \\
\hline Young's modulus & $550 \mathrm{Gpa}$ \\
\hline Bulk modulus & $439 \mathrm{Gpa}$ \\
\hline Shear modulus & $270 \mathrm{Gpa}$ \\
\hline
\end{tabular}

\section{MACHINING OF TITANIUM ALLOY}

Titanium and its alloys are used in the aerospace industry. They are combination of high specific strength and maintained at elevated temperature, fracture resistant, and corrosion resistant characteristics. They are also used in industrial and commercial applications of petroleum refining, chemical processing, surgical implantation, pulp and paper, pollution control, nuclear waste storage, food processing, electrochemical and marine applications [3]. Titanium parts are manufactured by conventional machining process. All types of machining operations as turning, milling, drilling, reaming, tapping, sawing, and grinding are applied in producing aerospace components [4]. The manufactured products are gas turbine engines, turning and drilling operations, airframe production and end milling, and drilling machining operations are used in titanium alloy.

\section{RESEARCH IN MAHINING OF TI 6AL 4V ALLOY}

Pioneering studies on the mechanics of chip during machining of titanium alloy or Ti-6Al-4V alloy have been conducted since the early 1950s, by Shaw and his coworkers [3, 4] and Boston et al. 5]. Komanduri et al. explained the mechanism of chip formation during the machining of titanium alloy more clearly. Previous studies on the machinability of Ti-6Al-4V alloy, micro structural changes, and mechanism of chip formation are explained below. 


\section{COOLING APPROACHES}

In machining, high temperature of the tool cutting edge, temperature influence on the rate of wear and the cutting tool. The heat generated at cutting operation is plastic deformation of chip formation and the friction between tool and work piece. Heat remains in the chips are conducted into the tool and work piece. Cutting process is used to cool and hot lubrication, and reducing tool wear and increasing tool life.

Several methods are used in cryogenic cooling, solid coolants and machining of hard machine materials. Researchers are looking for environment friendly methods in cooling approach.

\section{TOOL GEOMETRY AND FORCE ANALYSIS 3.1 GEOMETRICAL MODEL}

Already, the model was developed by (Altintas and Lee [1]); the same is reproduced here, for better understanding. Slight modifications have been made to suit the need of the present work. The flutes have a helix angle of $i_{0}$ at the ball-shank meeting boundary, due to reduction of the radius at the $x-y$ planes towards the tip in the axial (z) direction. The local helix angle $\mathrm{i}(\psi)$ along the cutting flute varies for constant helix lead cutters.

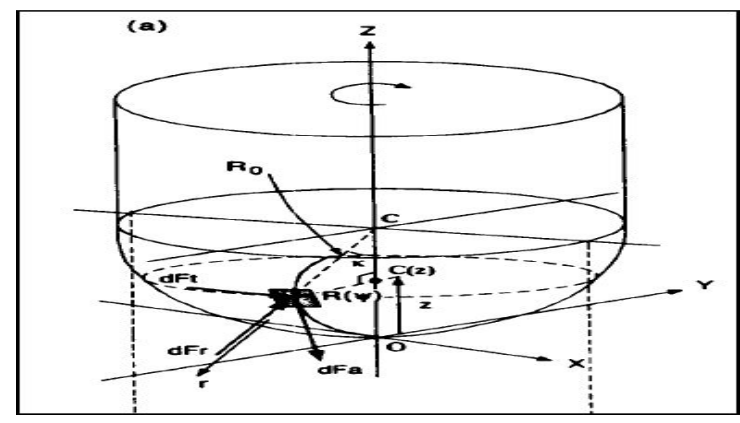

Figure 1: Geometry of a Ball Milling Cutter-1 (Altintas and Lee[1])

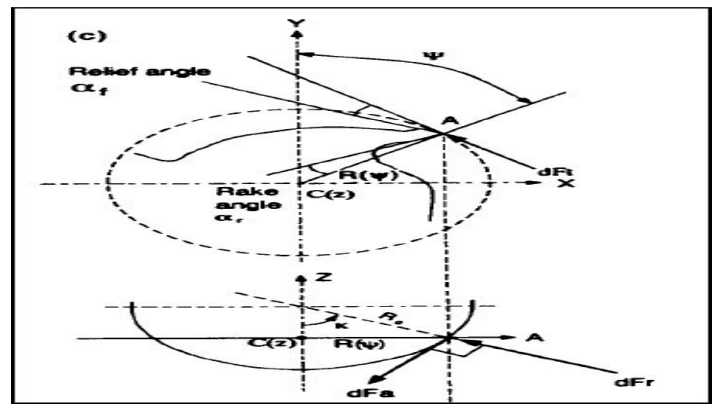

Figure 2: Geometry of a Ball Milling Cutter (Altintas and Lee[1])

\section{CAD MODEL OF END MILL CUTTER}

A flat end mill tool and ball end mill tool is modeled using Autodesk inventor software. The below represented models are of different geometrical parameters. In the present work, flat end mill and ball end mill are modeled to enhance the present models in the market available. For the development of these models, Autodesk inventor modeling software is used. Making the tool model involve lot of complexity, as lot of options are needed for design of tool like extrude, sweep, loft, chamfer, circular pattern etc. 


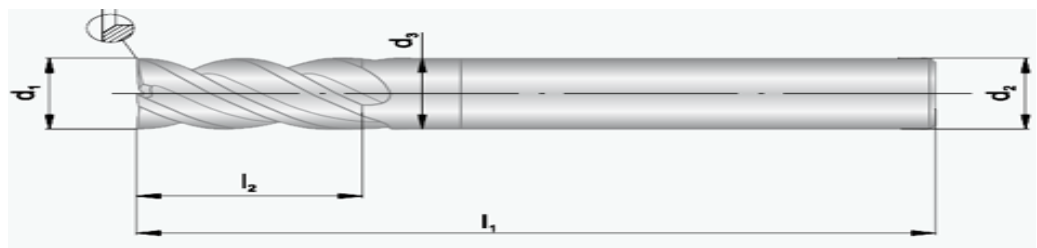

Figure 3: Flat End Mill Tool Geometry

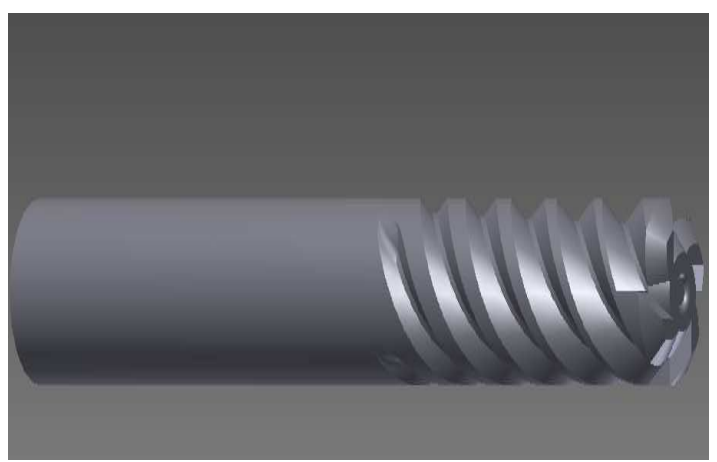

Figure 4: Cad Model of Ball End Mill-9

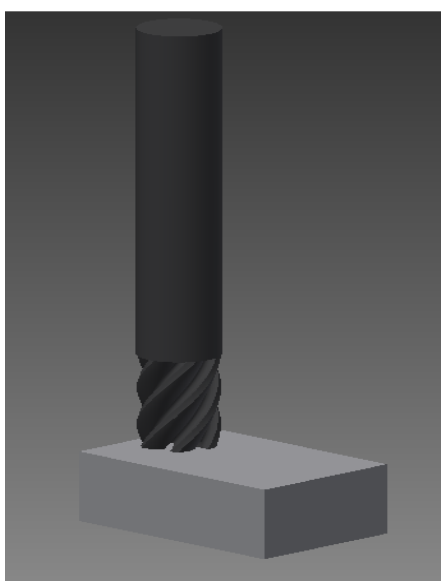

Figure 5: Assembly View of Work Piece and Flat End Mill

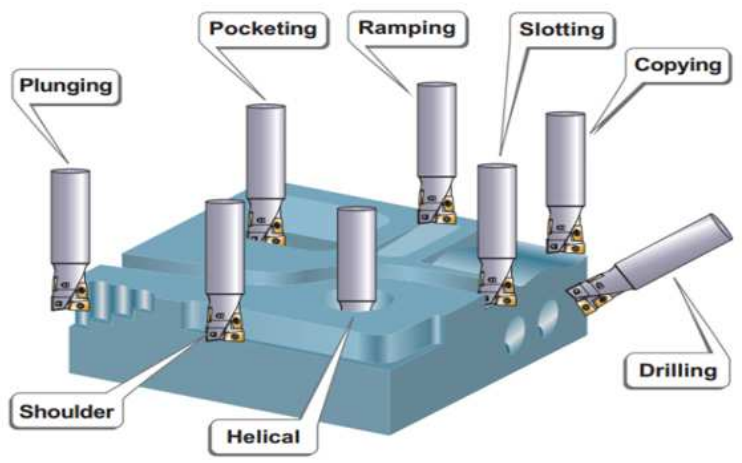

Figure 6: Effective Multifunctional Machining 
Table 2: End Mill Tool Geometry

\begin{tabular}{|c|c|c|c|c|c|}
\hline $\begin{array}{c}\text { Figure } \\
\text { No }\end{array}$ & $\begin{array}{c}\text { Tool Length }\left(\mathbf{l}_{\mathbf{1}}\right) \\
(\mathbf{m m})\end{array}$ & $\begin{array}{c}\text { Cutting } \\
\text { Length } \\
\left(\mathbf{l}_{\mathbf{2}}\right)(\mathbf{m m})\end{array}$ & $\begin{array}{c}\text { Shank } \\
\text { Diameter } \\
\left(\mathbf{d}_{\mathbf{2}}\right)(\mathbf{m m})\end{array}$ & $\begin{array}{c}\text { Cutting } \\
\text { Diameter } \\
\left(\mathbf{d}_{\mathbf{1}}(\mathbf{m m})\right.\end{array}$ & $\begin{array}{c}\text { No of } \\
\text { Flutes }\end{array}$ \\
\hline 4.3 & 66 & 28 & 10 & 8 & 6 \\
\hline 4.5 & 70 & 35 & 8 & 6 & 2 \\
\hline 4.6 & 70 & 37 & 8 & 6 & 4 \\
\hline 4.7 & 70 & 30 & 10 & 8 & 3 \\
\hline 4.11 & 68 & 30 & 10 & 9 & 4 \\
\hline
\end{tabular}

Theortical Work

Table 3: Details of Tool and Work Piece

\begin{tabular}{|l|l|l|}
\hline \multicolumn{3}{|c|}{ Material } \\
\hline Assignment & Tungsten carbide (tool) & Ti6al4v(work piece) \\
\hline Nonlinear effects & Yes & Yes \\
\hline Thermal strain effects & Yes & Yes \\
\hline \multicolumn{3}{|c|}{ Bounding Box } \\
\hline Length $x$ & $1.3401 \mathrm{e}-002 \mathrm{~m}$ & $5.5 \mathrm{e}-002 \mathrm{~m}$ \\
\hline Length y & $6.001 \mathrm{e}-002 \mathrm{~m}$ & $2.5 \mathrm{e}-002 \mathrm{~m}$ \\
\hline Length z & $1.3241 \mathrm{e}-002 \mathrm{~m}$ & $4 . \mathrm{e}-002 \mathrm{~m}$ \\
\hline \multicolumn{3}{|c|}{ Properties } \\
\hline Volume & $4.4007 \mathrm{e}-006 \mathrm{~m}^{3}$ & $5.5 \mathrm{e}-005 \mathrm{~m}$ \\
\hline Mass & $6.909 \mathrm{e}-002 \mathrm{~kg}$ & $0.24365 \mathrm{~kg}$ \\
\hline Centroid x & $-7.3386 \mathrm{e}-002 \mathrm{~m}$ & $-7.5886 \mathrm{e}-002 \mathrm{~m}$ \\
\hline Centroid y & $-3.9944 \mathrm{e}-003 \mathrm{~m}$ & $-4.8154 \mathrm{e}-002 \mathrm{~m}$ \\
\hline Centroid z & $7.08 \mathrm{e}-002 \mathrm{~m}$ & $8.6239 \mathrm{e}-002 \mathrm{~m}$ \\
\hline Moment of inertia Ip1 & $1.9473 \mathrm{e}-005 \mathrm{~kg} \cdot \mathrm{m}^{2}$ & $4.5177 \mathrm{e}-005 \mathrm{~kg} \cdot \mathrm{m}^{2}$ \\
\hline Moment of inertia Ip1 & $8.1855 \mathrm{e}-007 \mathrm{~kg} \cdot \mathrm{m}^{2}$ & $9.3907 \mathrm{e}-005 \mathrm{~kg} \cdot \mathrm{m}^{2}$ \\
\hline Moment of inertia Ip1 & $1.9473 \mathrm{e}-005 \mathrm{~kg} \cdot \mathrm{m}^{2}$ & $7.411 \mathrm{e}-005 \mathrm{~kg} \cdot \mathrm{m}^{2}$ \\
\hline
\end{tabular}

\section{RESULT ANALYSIS}

\section{Equivalent Stresses}
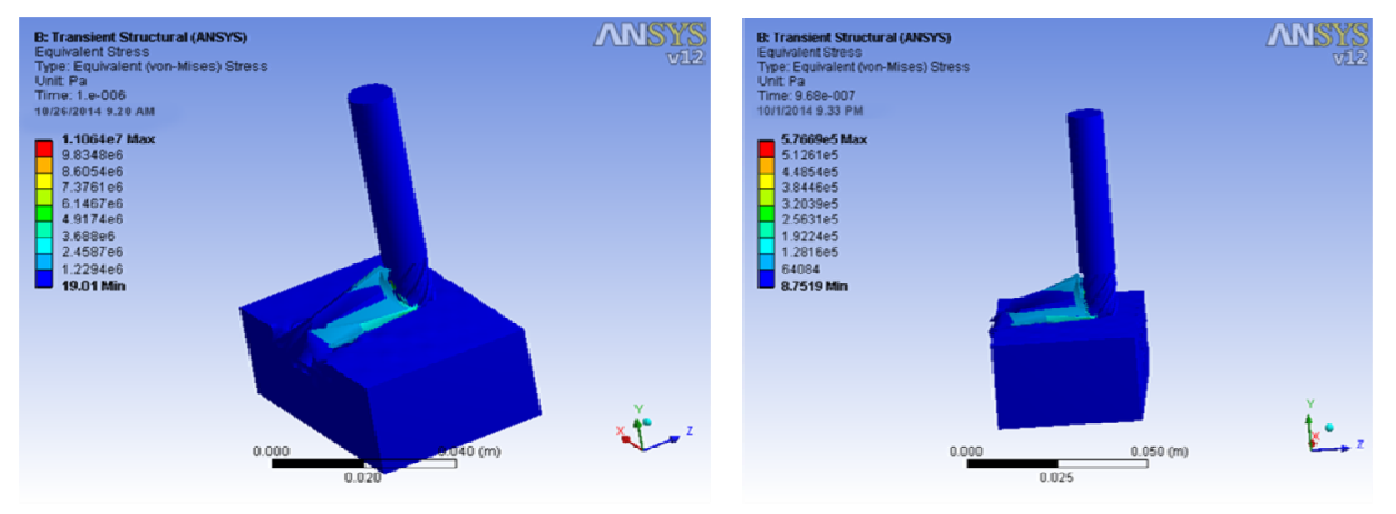


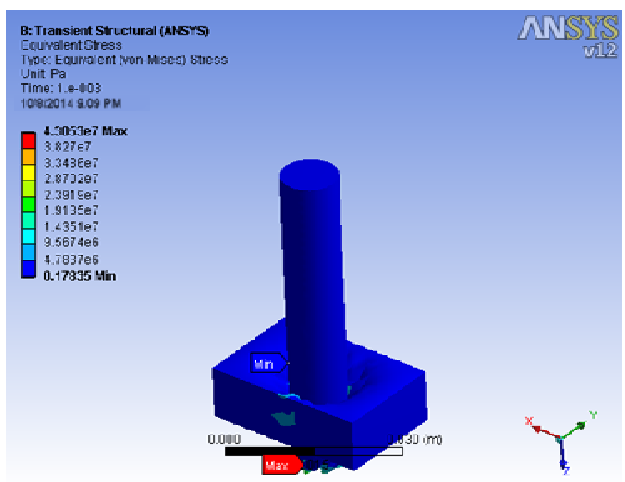

Figure 7

Total Deformation $1 \& 2$
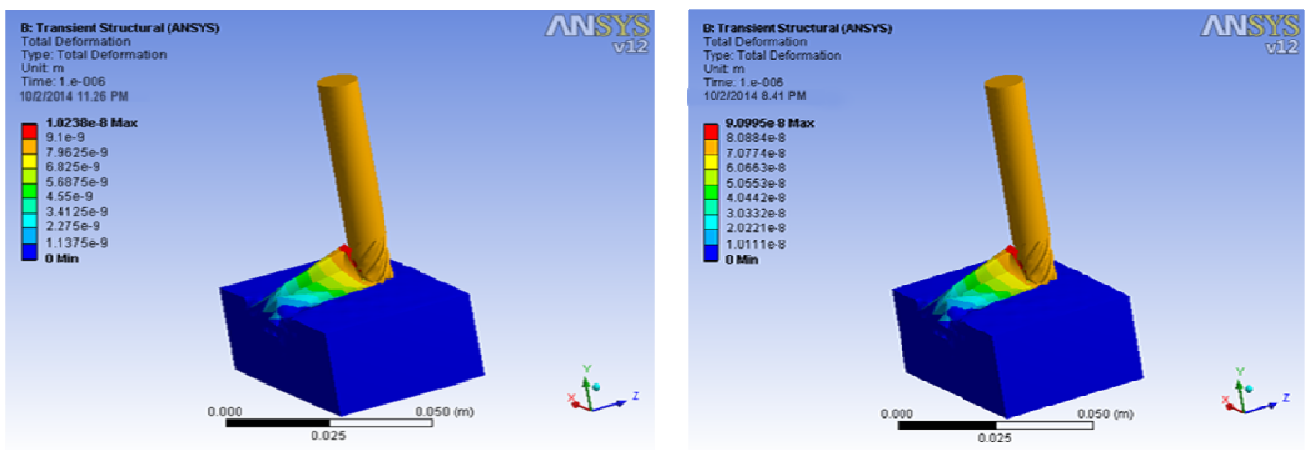

Figure 8

\section{Total Deformation 3\&4}
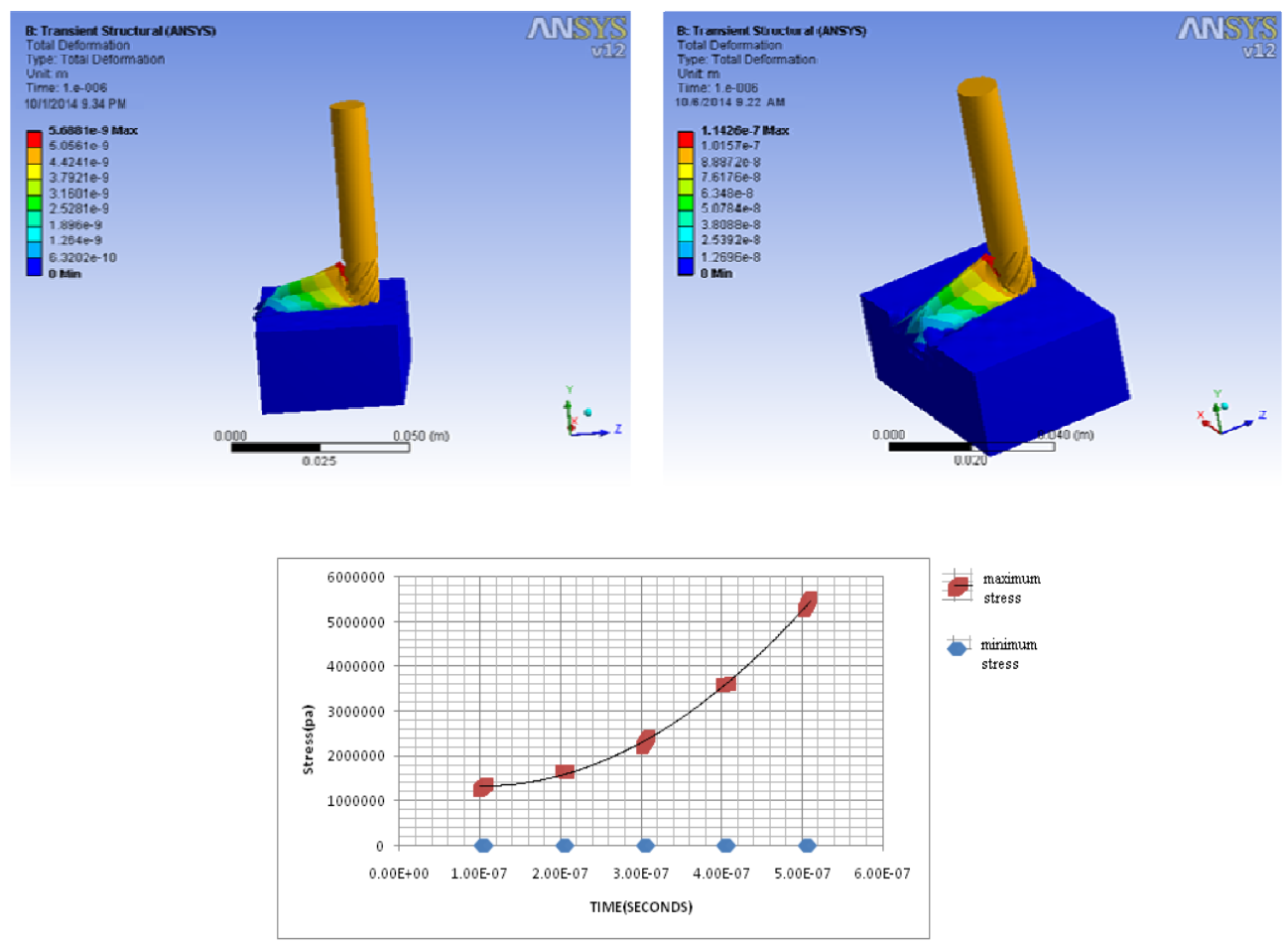

Figure 9: Relationship between Time(s) vs. Minimum and Maximum Stress (pa) 


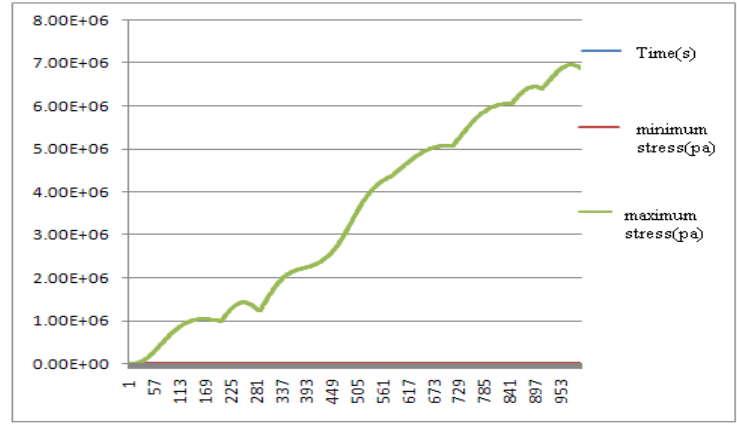

Figure 10: Relationship between Time(s) vs. Minimum and Maximum Stress (pa)

\section{CONCLUSIONS}

End mill tool forces while machining are calculated by using tool geometric equations, and optimum force is noted. Cutting conditions of milling machine are considered and cutting velocity, cutting forces and power are calculated for the better performance of milling cutter and milling machine. Cad model of end mill tool and end mill insert is developed using Autodesk inventor. Dynamic stress analysis is done using tungsten carbide end mill. Wide ranges of stresses acting over the tool are noted by changing the input parameters. The exact machining parameter is found for both low and high stresses that act over the tool. This will be useful for better life of tool.

\section{REFERENCES}

1. Pale and Y.Altintas,(1996)"Prediction of ball-end milling forces from orthogonal cutting data”, International Journal Machine Tools Manufacturing,vol 36,pp. 1059-1072.

2. Ahmad Yasir M., Che Hassan C.H, Jaharah A.G, Nagi H.E, Yanuar B and Gusri A.I,(2009)"Machinability of Ti-6Al-4V Under Dry and Near Dry Condition Using Carbide Tools",The Open Industrial and Manufacturing Engineering Journal,pp.1-9.

3. MC Shaw,SODirke, PA Smith, NH Cook, EG Loewen, CT Yang,(1954). Machining titanium, MIT Rep., (Contract AF 33 (600) 22674.

4. NH Cook(1953). Chip formation in machining titanium, In Proc. Symp. On Machining and Grinding Titanium, Watertown Arsenal, Watertown, MA, US Army Ordnance Corps.1-7.

5. Jayaram, K., Arun, C., \& Sakthivel, B. Design of Parallel Pipelined Feed Forward Architecture for Zero Frequency \& Minimum computation (ZMC) Algorithm of FFT.

6. OW Boston, RM Caddell, LV Colwell, RE McKee, KF Packer, PR Visser. Machining titanium, Final Rep. (Production Engineering Department, University of Michigan) ( USArmy Contract 20-018-ORD-11918 
